Esteban Marcos Dipaola

Universidad de Buenos Aires, Buenos Aires, Argentina

\title{
Narrativas imaginales de los cuerpos y las sexualidades: géneros y corporalidades en el filme Feos, sucios $y$ malos
}

Resumen: Partiendo de referencias teóricas relativas a la concepción de lo imaginal, es decir, los modos de constitución de los cuerpos y las sexualidades mediante imágenes, el análisis particular se concentrará en la película "Feos, sucios y malos" (Brutti, sporchi e cattivi) (1976) de Ettore Scola, con el objetivo de observar las visualidades del cuerpo y sus transformaciones cuando se presentan como exceso de las representaciones. En el filme los cuerpos, la sexualidad y los deseos marcan excesos de la representación de lo popular y, por eso mismo, una ruptura de la normalidad visual de los cuerpos. De esa forma, la representación de la mujer y de otras identidades sexuales se traman entre los ejes de una mirada normalizadora que la película eleva al grotesco como medio de su crítica. Con el planteo general relativo a las formas visuales de la sexualidad y los cuerpos, y con el análisis específico del filme "Feos, sucios y malos", se busca componer un artículo que indague en la crítica a las formas dominantes y normalizantes de inscribir las sexualidades en los dispositivos visuales de significación contemporáneos.

Palabras clave: cuerpos; sexualidades; imágenes; multiplicidad; clases populares

\section{Introducción}

El siglo XXI se caracteriza por la convivencia y comunicación en el contexto de una sociedad compuesta y atravesada por imágenes. Esas imágenes lo circundan todo y vuelven posible lo real, pero bajo el modo de lo visual. Esto es, convivimos entre muchos mediante imágenes, conectados por imágenes, relacionados entre imágenes, comunicados entre imágenes. Son las formas visuales las que organizan nuestro espacio comunitario. La configuración de un orden de lo visual también transfiguró la condición de los cuerpos y, más propiamente, la experiencia de los cuerpos. En la actualidad los cuerpos son visibles y se componen entre regímenes de visualidad. Como sugería Valentín Volóshinov:

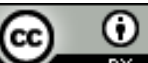

Esta obra está sob licença Creative Commons. 
"cualquier cuerpo físico puede ser percibido como imagen de algo" (2009, p. 26). El cuerpovisto manda y vuelve efectivo el dispositivo normalizador de la corporalidad, tanto como el de la mirada. Hay un cuerpo-visto y un cuerpo-que-vemos que se conforman y sitúan bajo las mismas lógicas normalizadoras de los regímenes de visualidad.

Las sociedades contemporáneas regidas en las formaciones visuales se materializan de acuerdo a las transformaciones de la cultura capitalista desde la segunda mitad del siglo XX en adelante. Tales transformaciones tuvieron su correlato crítico en los cuestionamientos tempranos a la "sociedad del espectáculo" (Guy DEBORD, 1999), o también a la "cultura del simulacro" (Jean BAUDRILLARD, 1987). Pero con la aparición del mundo de la red y la virtualización de las relaciones al ritmo del avance permanente de las "nuevas tecnologías de comunicación", aquellas transformaciones evidenciaron una acentuación que involucró la resonancia de tecnologías de los cuerpos y de la subjetividad. En ese sentido, José Luis Brea (2007) afirma que asistimos a la potencia de un "capitalismo cultural electrónico", cuya industria preponderante y más eficiente es la "industria de la subjetividad". El capitalismo cultural contemporáneo se encarga de producir cuerpos visuales y, por eso mismo, estrictamente reales.

De manera similar se entiende que esas nuevas disposiciones de subjetividad se entrelazan en las formas de control de la "sociedad conexionista", donde las nuevas tecnologías y los recursos digitales representan la organización de una "cibercultura" (Fernando PEIRONE, 2012). Una nueva composición de la subjetividad aparece como espacio de visibilidad, y desde la masificación de un medio como internet, la subjetividad y los cuerpos empezaron a inscribirse como prácticas de visibilidad, mediante lo que Paula Sibilia denomina "usos confesionales":

La subjetividad se constituye en el vértigo de ese torrente discursivo, es allí donde el yo se realiza. Por lo tanto, usar palabras 0 imágenes es actuar: gracias a ellas podemos crear universos y con ellas construimos nuestras subjetividades. (SIBILIA, 2008, p. 38)

El régimen de visualidad que aquí propongo pensar, se relaciona con lo que denominaremos sociedades imaginales, ${ }^{1}$ es decir, un tipo de sociedad -la contemporáneaque regula sus modalidades de acción y comunicación mediante imágenes, y en la cual la distancia entre la experiencia social propiamente dicha y las imágenes es indiscernible. Se trata de sociedades cuyas normativas de sociabilidad tienen efectividad en el marco de relaciones que se configuran como imágenes. De este modo, lo que debe entenderse en esa categorización de lo imaginal es, precisamente, la confluencia entre lo social y las imágenes; adoptando, entonces, una definición amplia de la noción de imagen que contenga no solamente la consideración de imágenes televisivas, cinematográficas, publicitarias, etc., sino que comprenda las lógicas de consumo, las vestimentas, los gustos, las modas, etc. como imágenes y como formas propias de vínculos imaginales. Aparece, así, un ordenamiento visual de la experiencia social y cultural contemporánea.

En el contexto de estas lógicas y dispositivos de enunciación y visualización de los cuerpos, se instituye una nueva cultura normalizadora y normativa que introduce dentro de su régimen de visualidad el cuerpo anómalo, al punto de que es la anomalía la que corrige el sistema normalizador de la visualidad. Judith Butler condujo la noción de performatividad hacia la concepción de un "cuerpo-discurso", en ese sentido, afirmaba

\footnotetext{
' Ver Esteban Dipaola (2011). Investigaciones relativas a la categoría de lo imaginal también se vienen realizando en el marco del Proyecto y financiamiento para la Investigación FONCyT de la Agencia Nacional de Promoción Científica y Tecnológica de Argentina, cuya denominación es: "Producciones imaginales: cruces entre lo social y lo visual en las subjetividades contemporáneas".
}

1460 Estudos Feministas, Florianópolis, 25(3): 1459-1471, setembro-dezembro/2017 
que "el discurso debe entenderse como un conjunto de cadenas complejas y convergentes cuyos 'efectos' son vectores de poder" (2008, p. 267). De esta manera el "cuerpo sexuado" se conforma a partir de condiciones para nada estables de la normativa de la performatividad. En similar aspecto, asumimos que la cultura capitalista contemporánea interviene de acuerdo a lo que denominamos regímenes de visualidad. Es una producción industrial de lo visible de los cuerpos que normaliza incluso lo que otrora fuera considerado anómalo para integrarlo a una cadena de producción que es la del cuerpo-visto. Ese cuerpo-visto es el conjunto de toda una cadena que se materializa y serializa en el cuerpoconsumo, el cuerpo-moda, el cuerpo-ocio, etc. Una lógica cultural del poder enfocada en hacer cuerpos, producir cuerpos.

En el marco de este artículo, ese análisis general que introducimos y proponemos se concretará mediante la intervención del filme italiano Feos, sucios y malos (Brutti, sporchie cattivi, en el idioma original de la película), dirigido por Ettore Scola, y estrenado en el año 1976. En este filme es importante visualizar las formas de convivencia de cuerpos, sexualidades, deseos, que en su anomalía, sin embargo, desterritorializan su propia condición de subjetividad, mostrándose en ese punto la modalidad de las industrias de la subjetividad para normalizar en un campo de visualidad las figuras del cuerpo.

Esto que se expone es posible de contrastar señalando la forma 'objetivista' que se propone la película, aun cuando se corresponda con la idea típica de la comedia italiana. De hecho, el propio director indicó que en una primera intención se propuso filmar un documental sobre la periferia de Roma y los modos de expulsión que la burguesía romana utilizaba para alejar ese elemento extraño que significaba el pobre. ${ }^{2}$ Sin embargo, la aproximación a eso relegado de la sociedad italiana determina que Scola acabe filmando el registro de vida de esa pobreza de Italia con las claves del 'neorrealismo'. Así, lo que hace el director es excavar en la realidad no solo de la pobreza y sus formas grotescas, sino en las maneras que esa situación significa una discursividad social que hace visible al pobre únicamente sobre semejante dimensión.

De todos modos, aunque esta impronta neorrealista sea la que configura una estética, la película se realiza a mediados de la década del 1970, cuando el neorrealismo y la posguerra sobre la que nació ya transcurrió desde hace algunos años, por lo cual las imágenes de esta película de Scola más verosímilmente remiten a las transformaciones del capitalismo internacional de la época y, principalmente, al repliegue del Welfare State. ${ }^{3}$ De ahí, que algunas escenas y líneas argumentativas se concentren en las dificultades para solicitar los beneficios sociales a los que esos pobres estaban acostumbrados a recibir. También en este punto es esencial remarcar la transformación de la pobreza que retrata Feos, sucios y malos: si en las películas neorrealistas más clásicas los pobres aparecían como feos y sucios, empero, se desprendía de ellos un halo de bondad y de solidaridad que moldeaba sus vínculos sociales, en cambio, en Scola-como el título

\footnotetext{
${ }^{2}$ Estas declaraciones de Ettore Scola corresponden a sus dichos durante el festival de Cannes del que participó el filme y con el que ganó la Palma de oro. Las mismas son citadas en la nota de la web: http:// pedrovaalcine.blogspot.com.ar/2016/02/ettore-scola-feos-sucios-y-malos.html?view=sidebar (Última revisión: 28/04/2016).

${ }^{3}$ Si se pone en contexto histórico tradicional, la película es estrenada apenas tres años después de que se desatara la "crisis mundial del petróleo", que reconfiguró los Estados capitalistas en el mundo y promovió transformaciones sustanciales en los modelos económicos, con una orientación hacia los servicios y el capital financiero por sobre el productivo o industrial. Algunos autores han denominada esta etapa como postindustrial poniendo de relieve el cambio en lo económico y otros como posmoderna haciendo mayor hincapié en la dimensión cultural. En cualquier caso, se trata de una modificación del modelo de acumulación que en términos de David Harvey (2008) determina el paso de la "acumulación rígida" a la "acumulación flexible".
} 
indica-, además de feos y sucios son malos, es decir, está resquebrajado ese lazo que reaseguraba el bien común con otro.

En definitiva, ese contexto social de Italia en la época de alteración y crisis de las economías capitalistas lo expresan las imágenes de Scola, mediante cambios en la vida social que se vivifican en los cuerpos, en las sexualidades, los deseos y, al fin, en la puesta en común de sensibilidades que la sociedad visibiliza como lo atrofiado y lo ajeno.

Esto que se indica puede ser evaluado, y es lo que se propone realizar el artículo en adelante, de acuerdo a tres coordenadas de análisis: a) lógica de los muchos; b) lógica del menos; c) lógica de multiplicidad.

\section{Lógica de los muchos y régimen de visualidad}

Primeramente, la película Feos, sucios y malos nos introduce en el nauseabundo medio del hacinamiento, y en ese acercamiento al mundo, mediante planos cerrados, muestra el orden visual de la pobreza: cuerpos convivientes y pegados, amontonados. Una lógica de cuerpos juntos que solo hacen muchos. En esos primeros planos del filme se compone un régimen de visualidad propio de una cultura de la exclusión; una cultura que expulsa a esos cuerpos a una convivencia inhóspita y que por eso mismo arroja los cuerpos a un estado fuera de la conducta social esperada. Son cuerpos y son sujetos que comen de manera grosera, que conviven de acuerdo a condiciones de sociabilidad anómalas, que hablan y gritan de formas poco sensatas. En cierta manera, ese régimen de visualidad enseña la manifestación de corporalidades que no se inscriben en las formas previstas de regulación social. Son excesos, y por eso su modo de existencia es el hacinamiento. La incorporación de las normas que definen prácticas en la cultura no es ajena a esos cuerpos, pero todavía permanece como exterioridad y, por tanto, la modalidad de regulación es todavía la inscripción de los cuerpos como agentes extraños. Judith Butler entiende ese tipo de regulación según ciertas prácticas de inscripción del género:

La práctica mediante la cual se produce la generización, la incorporación de normas, es una práctica obligatoria, una producción forzosa, aunque no por ello resulta completamente determinante. Puesto que el género es una asignación, se trata de una asignación que nunca se asume plenamente de acuerdo con la expectativa, las personas a las que se dirige nunca habitan por entero el ideal al que se pretende que se asemejen. (BUTLER, 2008, p. 324-325)

Desde esta perspectiva, se comprende como lógica de los muchos a ese régimen de visualidad que consiste en inscribir exclusiones y concebir una determinada manera de experiencia cultural desde ello. Se trata de producir formas visibles que delimiten qué cuerpos son aceptados en la cultura y cuáles se desechan. En fin, una lógica de inscripción de los cuerpos que instituye demarcaciones mediante los significados de un orden de lo visible, que se regulan sobre el régimen de visualidad mencionado.

Específicamente, en la película que se analiza, este régimen de visualidad se materializa como una mirada sobre las clases populares, y en eso funciona el efecto de exclusión: lo popular es lo que no pertenece ni se asemeja -y no podría hacerlo- a la cultura formal y burguesa. Es el cuerpo que no se corresponde con las imágenes de los cuerpos que sí son parte y es, a su vez, el cuerpo que no se condice con los regímenes de significación validados por la cultura. En Feos, sucios y malos se abordan los cuerpos que están fuera, y de esa manera se expone críticamente la figura culturalmente sostenida acerca de lo popular, es necesariamente aquello que no corresponde, que no pertenece.

Ahora bien, si se indaga cómo aborda este régimen de visualidad articulado mediante exclusiones ese dilema de lo popular, la respuesta que aparece es que lo realiza 
inscribiendo aquello que pertenece y es propio de las sociedades capitalistas, pero que por no ser bien visto debe ser expulsado, precisamente como características esenciales y naturales de lo popular. De esta manera, la película de Scola hace visible los estereotipos sobre la representación de la mujer en la cultura popular, es decir, la mujer es un cuerpo feo y generalmente gordo, demacrado y mal vestido, que únicamente se dedica a tareas domésticas y la crianza de los hijos, y que debe aceptar tener relaciones sexuales cuando su marido lo disponga, además de no juzgar si éste es infiel o se acuesta con otras mujeres. De la misma manera, la figura del padre es mostrada como un ser grosero, autoritario, alcohólico y poco afectivo con sus hijos y esposa. En esta misma línea, Ana Fernández afirma que:

Pensar los cuerpos [...] es hacerse cargo de los cuerpos "sucios" y "feos" de los expulsados que exponen y manifiestan su exclusión, que golpean redundando, que no ocultan y se resignan en su desamparo, sino que obscenamente ponen a la vista lo que se ha hecho con ellos. (FERNÁNDEZ, 2007, p. 269)

En síntesis, pensar los cuerpos es reflexionar sobre el régimen de visualidad que los hace posibles y que determina las formas de inscripción y exclusión. En otros términos, obliga a observar cuáles son los significantes hegemónicos que definen su inscripción material en un específico orden de lo visible. En este aspecto, no se limita ese orden de lo visible a una matriz de dominio heterosexual, sino que también incorpora identificaciones de clase, religiosas, étnicas, etc., que, como afirma Silvia Citro, "lo hacen con sus propias formas, intensidades y violencias" (CITRO, 2009, p. 109).

Además, también se revelan estereotipos para definir y hacer visible una mirada sobre la prostitución y los sujetos transexuales. En este caso, tanto la prostitución como el travestismo son parte de una misma condición, es decir, quien se define como travesti lo hace porque va a prostituirse, ${ }^{4}$ pero también son aquellos que solo pueden vivir en ese territorio, no pueden estar dentro de los espacios normalizados de la sociedad capitalista, ellos son lo que queda fuera, los cuerpos que aun siendo vistos en su labor, no deben ingresar en el régimen de visualidad y en su normativa hegemónica. Son cuerpos sin forma, esto es, carentes de las condiciones y normas propias de la corporalidad generalmente aceptada.

Sobre el eje de estas precisiones expuestas, es importante comprender el modo en que Ettore Scola busca representar siempre estos cuerpos y sus acciones mediante el exceso. Se propone una estética de cuerpos embrutecidos, pero se lo hace para evidenciar el dominio del régimen de visualidad actuante. Lo que el director muestra es la mirada que se materializa sobre lo popular como algo ajeno y anómalo. En esto consiste la condición cuerpo-visto/ cuerpo-que-vemos: cuando las reglas de socialidad de una cultura particular crean la imagen del cuerpo, ya asumen qué cuerpos serán excluidos; el cuerpo-que-vemos es un cuerpo-ya-visto, es decir, ya producido entre los significantes hegemónicos de la realidad imaginal. De acuerdo con todo ello, las imágenes del vínculo familiar tampoco se corresponden con lo estipulado dentro de lo normal, y así todo se singulariza y localiza como

\footnotetext{
${ }^{4}$ Patricia Navarro Pérez ofrece una tipología de distinciones para las identidades trans:

"- Transgénero. Las personas transgénero son aquellas que cuestionan la necesidad de escoger entre los roles masculino y femenino y que no consideran necesario establecer una correspondencia entre sexo y género mediante la transformación corporal.

- Travesti. Son aquellas personas que de forma voluntaria y frecuente se visten con ropas comúnmente asignadas al género opuesto. En Latinoamérica en cambio, este concepto se emplea como sinónimo de lo que aquí conocemos como transgénero.

- Intersexual. Comúnmente conocidas como hermafroditas, son personas que presentan características sexuales masculinas y femeninas de manera simultánea, y en grados variables" (NAVARRO PÉREZ, 2010, p. 8).
} 
exceso: de hijos, de personas, de cuerpos, de relaciones, etc. Cada cual tiene relaciones sexuales con cualquiera y en el mismo espacio de convivencia, configurándose una forma de vida desprovista de condiciones normales, y, por ello mismo, excedida de lo posible en un específico régimen de visualidad. Lo que se desordena con esto es la imagen higienista que se ha heredado respecto al vínculo familiar (Ana AMADO y Nora DOMÍNGUEZ, 2004).

Estas reflexiones pueden significarse y mostrarse mejor aludiendo a dos escenas características de la película: en primer lugar, apenas comienza, luego de una sucesión de planos que indican el amanecer reciente, las imágenes nos representan el hacinamiento y la constricción de todos esos cuerpos a un pequeño espacio, donde algunos de éstos se esparcen semi desnudos y otros comienzan a vestirse, otros cargan con bebés y mamaderas, una mujer se depila, otro habitante del lugar lava sus pies en una fuente, algunos se pelean y la abuela desayuna sobre una diminuta mesa y sentada en su silla de ruedas. A su vez, la forma en que esta situación se expresa en las imágenes es un plano secuencia, que, al no poseer corte, tiene la virtud de significar todo ello en una continuidad irreductible, donde todo se aparece conjunto, mezclado y confuso. En segundo lugar, esa imagen higienista a la que referimos como 'deber ser' del vínculo familiar en las sociedades es desbaratada en la escena que Giacinto (Nino Manfredi): luego de haber visto a la mujer de uno de sus hijos tener una relación sexual con otro de ellos, por la noche, lleva a esa mujer al baño y bajo la amenaza de contar lo que vio, obliga a esa misma persona a mantener relaciones sexuales con él. Así, estas imágenes del filme que referimos representan esas formas del exceso y promiscuidad correspondido como característica de lo popular.

Por todo esto, se comprende que el exceso es la dimensión mediante la cual Scola no solo muestra la condición del régimen de visualidad de los cuerpos propio de las sociedades capitalistas, sino que es, además, la figura a través de la cual se permite transfigurar el eje de análisis desde ese campo descriptivo del régimen hacia otro más explicativo, que se relaciona con lo que llamamos aquí dispositivo de visualidad. En fin, partiendo de esa dimensión del exceso es que resulta posible pasar de la lógica de los muchos a la lógica del menos y, con ello, pensar las condiciones y el funcionamiento del dispositivo de la visualidad de los cuerpos.

\section{Lógica del menos y dispositivo de visualidad}

Esas representaciones descriptas, y que aparecen bajo el manto excluido de lo popular, permiten también pensar la señal crítica de una forma de mirada, y prestar atención al dispositivo de codificación y normalización que las sociedades capitalistas promueven. La condición del exceso establece un pasaje de la lógica de los muchos a la lógica del menos, porque produce una segmentación y clasificación de los cuerpos. De este modo, el régimen de visualidad se convierte en un dispositivo capaz de hacer el cuerpo visible. Otro tipo de subjetividad que puede introducirse en la experiencia de una cultura de lo normal siempre y cuando se proceda a la clasificación de esas corporalidades. En perspectiva de algunos análisis propuestos por Judith Butler, puede argumentarse que "hay cuerpos que importan más que otros" (BUTLER, 2008, p. 49), sin embargo, ese dispositivo que torna visible cualquier cuerpo constituye la ilusión de armonía y equivalencia. Por eso, también Butler remite a una revisión foucaultiana del poder para pensar el ejercicio de las clasificaciones y la normalización de los cuerpos dentro de un campo visible:

A esta comprensión del poder como producción obligada y reiterativa es esencial agregar la idea de que el poder también funciona mediante la forclusión de efectos, la producción de un 'exterior', un ámbito inhabitable e ininteligible que limita el ámbito de los efectos inteligibles. (BUTLER, 2008, p. 49)

1464 Estudos Feministas, Florianópolis, 25(3): 1459-1471, setembro-dezembro/2017 
En esta línea, lo que es necesario pensar es los tipos de cuerpos que son producidos, es decir, materializados como cuerpos normales y representados en el modo constituyente del poder. Por eso se entiende a la lógica del menos como de segmentación y clasificación de los cuerpos, pues define un modo de ver, constituye una mirada que hace posible la existencia del cuerpo.

De este modo, si en la lógica de los muchos el modelo prevaleciente era el hacinamiento y la consagración de una especie de todos entre todos y todos contra todos, donde había enfrentamientos por dinero, por comida, por mujeres, por la posición de autoridad, etc., por su parte, la particularidad de la lógica del menos es la definición de la situación, la producción de un cuerpo típico, la reglamentación de un espacio común de convivencia. De acuerdo a estas perspectivas, los cuerpos se vuelven visiblemente aceptados, incorporados en el régimen de visualidad, pero por la condición productiva del dispositivo. En definitiva, se trata de un dispositivo de visualidad que enseña a ver el cuerpo del otro, de lo popular ya no como algo ajeno, sino como qquello que, siendo de otra manera, no deja de ser normal. Una ampliación del campo de lo visible y que es alcanzada a costa de que el dispositivo de visualidad componga prácticas de los cuerpos condicionalmente aceptadas y reguladas.

En la película de Ettore Scola, esto procede narrativamente mediante maneras de integración que los sujetos deben estabilizar para "vivir en sociedad", y acorde a la institucionalidad propia de la cultura compartida. Así, los personajes se higienizan y visten bien para conseguir trabajo, para concurrir a citaciones policiales en la comisaría de la zona o para acudir a diferentes tipos de instituciones que requieren ese tipo de formalidades estables para consagrar algún tipo de aceptación de una relación. A su vez, en lo que refiere al aspecto de forma y técnico del filme, tanto el montaje como los planos que presentan estas situaciones mantienen presente la imagen de una inequidad constitutiva de la relación, al mostrar siempre por debajo de una línea de la mirada a los personajes menos favorecidos de la relación. Entonces, aun persistiendo la desigualdad en la relación compuesta, lo importante es que el dispositivo de visualidad constituye una práctica del cuerpo que hace posible su integración en el régimen de visualidad. El cuerpo se transforma porque sus prácticas se vuelven adecuadas para una cultura de la normalidad y las normativas institucionales que le corresponden.

Es esa la manera en que funciona ese dispositivo de la visualidad: hace cuerposque-vemos de acuerdo a las reglas de cuerpos-vistos; determina lo estable de los cuerpos y del sexo y, por ello, es que produce segmentaciones y clasificaciones. Consagra la lógica del menos como contraparte de la lógica de los muchos, puesto que aquí ya no nos encontramos con el cuerpo hacinado y promiscuo, desorganizado en su experiencia cotidiana y desordenada en su vitalidad social; ahora se tiene un cuerpo definido, regimentado, un cuerpo y un sexo que no se mezcla, sino que ahora contiene condiciones normativas específicas de convivencia con los otros cuerpos.

Precisamente, de esto se trata el dispositivo de visualidad como productor de prácticas específicas y estables de los cuerpos que son integrados en un régimen de visualidad.

Siguiendo este hilo argumentativo, resulta útil emplear nuevamente las palabras de Judith Butler para reflexionar sobre esto que indicamos:

Lo esencial estriba entonces en que la construcción no es un acto único ni un proceso causal iniciado por un sujeto y que culmina en una serie de efectos fijados. La construcción no solo se realiza en el tiempo, sino que es en sí misma un proceso temporal que opera a través de la reiteración de las normas; en el curso de esta reiteración el sexo se produce y a la vez se desestabiliza. Como un efecto sedimentado de una práctica reiterativa o ritual, el sexo adquiere su efecto naturalizado y, sin embargo, en 
virtud de esta misma reiteración se abren brechas y fisuras que representan inestabilidades constitutivas de tales construcciones, como aquello que escapa a la norma o que la rebasa, como aquello que no puede definirse ni fijarse completamente mediante la labor repetitiva de esa norma. Esta inestabilidad es la posibilidad desconstituyente del proceso mismo de repetición, la fuerza que deshace los efectos mismos mediante los cuales se estabiliza el "sexo", la posibilidad de hacer entrar en una crisis potencialmente productiva la consolidación de las normas del sexo. (BUTLER, 2008, p. 29-30)

Entonces, si las condiciones del régimen de visualidad delimita el campo de lo permitido entre los cuerpos, es decir, aquello que es visible y, por ello, pasible de ser relacionado, comunicado, comprendido, y lo que no lo es; por su parte, el dispositivo de visualidad produce los cuerpos y, con estos, las prácticas que normativamente son aceptadas en el campo de lo visible. El dispositivo de la visualidad, en definitiva, hace posible una determinada experiencia del cuerpo y la potencia reiterativa de una forma de ver que lo normaliza y fija. Así, lo que se crea es una imagen del cuerpo y del sexo aprehendida por todos, una práctica de la visibilidad de los cuerpos.

En Feos, sucios y malos esto se evidencia, como hemos expuesto mediante la puesta en escena y las decisiones de montaje y sucesión de planos, pero sobre todo en el modo que se representa el ejercicio de integración de esos cuerpos a la cultura burguesa. Los modos propios de lo popular son "higienizados" y remodelados para su presentación por fuera de su registro habitual y cotidiano. ${ }^{5}$ Debe crearse el cuerpo-que-vemos sobre las condiciones de cuerpos-vistos.

Pero justamente donde la segmentación y la clasificación representan sus determinaciones y delimitaciones, también se asiste al cuerpo inestable, inespecífico, el cuerpo que pone en crisis el régimen de lo visible. Cuando Butler explica que hay una inestabilidad que pone en crisis el proyecto repetitivo de la norma, en ese mismo punto puede pensarse en línea con la película Feos, sucios y malos, que el contrapunto entre la lógica de los muchos sostenida en el hacinamiento y la promiscuidad y la lógica del menos de la segmentación y clasificación, abre un lugar intersticial para otro tipo de lógica que no se centra ni condiciona en las anteriores, sino que inscribe modalidades nuevas de la sexualidad y de las prácticas de los cuerpos. Se trata de lo que llamaremos una lógica de multiplicidad, con la que se modifica el territorio sobre el cual los cuerpos se expresan, relacionan y vuelven visibles. Es una lógica que hace efectiva la crisis de la representación normativa y normalizadora de los cuerpos reasumiendo la dimensión del exceso que detalláramos anteriormente. Es por el exceso que la representación cede ante una perspectiva de multiplicidad que nada tiene que ver con un conjunto de muchos ni con un régimen clasificatorio. La lógica de la multiplicidad es la que posibilita la emergencia de otro(s) cuerpo(s), la concreción de prácticas que desafían el régimen de visibilidad establecido y, conjuntamente con esto, ponen en movimiento los componentes críticos de las normativas sobre el sexo de la cultura capitalista.

\section{Lógica de multiplicidad y prácticas de desterritorialización}

Una vez establecida la ruptura de los binarismos esenciales naturaleza/cultura, sexo/ género y habiendo ya considerado que en cualquier caso se trata de una construcción específica de la cultura (BUTLER, 2008), es plausible entender que tanto si nos situamos

\footnotetext{
${ }^{5}$ Es ejemplar la escena en que el protagonista, Giacinto, se encuentra en la comisaría, porque allí se revela el modo en que las formas de usos del lenguaje, la vestimenta e, incluso, la postura corporal se modifican para evitar la represalia policial. Un campo amplio de la comunicación y presentación social es expuesto en esa escena para mostrar el registro de lo visible que compone determinado tipos de cuerpos.
}

1466 Estudos Feministas, Florianópolis, 25(3): 1459-1471, setembro-dezembro/2017 
sobre la lógica de los muchos, como si lo hacemos sobre la lógica del menos, siempre estamos respondiendo a las maneras de organización preestablecidas por las normativas institucionales de la cultura. Sin embargo, lo que entendemos por lógica de multiplicidad permite entrever una modalidad distinta del discurso donde los cuerpos y el sexo, así como también el género no pueden representarse porque ahora son singularidades desprovistas de una imagen previa, son aquello que por el propio devenir de sus prácticas no dejan de producirse como algo nuevo, como algo diferente.

Esta lógica de la multiplicidad es expresada en las narrativas y las imágenes de Feos, sucios y malos, haciendo de la dimensión antes mencionada del exceso aquello que huye de todo principio de representación y adecuación para corresponderse permanentemente con una expresividad diferente. ${ }^{6}$ Así, las figuras de la sexualidad y del deseo que en el marco de una lógica de los muchos podían ser vistas como algo promiscuo y, por esto mismo, ajeno a la normalización de la cultura, y que en la lógica del menos se mostraban como algo estabilizado por las propias relaciones institucionales normativas de la cultura, se expresan ahora como prácticas capaces de transformar incluso a la propia norma o excederla en cuanto modelo para producir algo distinto. Son prácticas de desterritorialización que promueven otras visualidades y evidencian maneras distintas de ver. Por esto, aquí ya no hay una dicotomía regulativa cuerpo-visto, cuerpo-que-vemos, sino experiencias de los cuerpos que desplazan perpetuamente la práctica del ver.

En otros términos, y siguiendo lo que postulaban autores como Gilles Deleuze y Félix Guattari en El Anti Edipo (1995) respecto a que el cuerpo es devenir, lo que tenemos es que es necesario crear el propio cuerpo. El deseo es conformador de un organismo en tanto se lo entiende como una máquina que produce, que crea. Así, una "máquina deseante" hace lugar a un cuerpo-otro, un "cuerpo sin órganos" que puede ser siempre un cuerpo cualquiera, un espacio cualquiera. Hacerse un cuerpo es desterritorializarlo, entonces ya no hay unidad ni identidad, simplemente devenir: devenir mujer, devenir animal, devenir máquina, etcétera. La idea de que los organismos forman un cuerpo queda desplazada, pues el organismo es el enemigo natural del cuerpo. El cuerpo sin órganos es conexión y distribución, desplazamiento esquizofrénico que solo sigue las metamorfosis de los flujos deseantes. En palabras de los pensadores:

El cuerpo sin órganos no es Dios, sino todo lo contrario. Sin embargo, es divina la energía que lo recorre, cuando atrae a toda la producción y le sirve de superficie encantada y milagrosa, inscribiéndola en todas sus disyunciones. (DELEUZE y GUATTARI, 1995, p. 21)

Entonces, es posible creer en Dios aunque el cuerpo sin órganos no sea Dios, puesto que si se puede creer en el cuerpo sin órganos es como señor de esa disyunción, de todos los desvíos, de los más íntimos desplazamientos, de cualquier fuga del deseo, que hace explosión en nuestro cuerpo volviéndolo siempre un cuerpo otro, no un cuerpo genital, no un cuerpo macho, no un cuerpo hembra, sino siempre -y por venir- un cuerpo otro.

De esta forma, si retomamos las maneras de expresión estética que todo ello tiene en la película de Scola, es pertinente ahora comprender cómo esa lógica de multiplicidad que se actualiza desde el desplazamiento del deseo como deterritorialización de la sexualidad se hace efectiva en el filme a partir de la puesta en escena que el director proyecta para exagerar la condición de lo popular como algo que excede a la representación normativa

"En este sentido, el concepto de "exceso" que aquí se propone se asemeja en buena medida a las ideas de Georges Bataille (2006) sobre el erotismo y los cuerpos, considerando el justo sentido que este autor otorga al excedente como borramiento del límite, como algo que permanece siempre por fuera de toda práctica, pero aun así siendo condición de posibilidad del todo. Por eso el "exceso" es lo imposible, el lugar sin sujeto ni objeto; para Bataille es la muerte, es decir, el lugar donde ya no es posible la representación. 
de la cultura capitalista. ${ }^{7}$ Esa puesta en escena es la que evidencia las prácticas de los cuerpos como ejercicio de una desterritorialización de la sexualidad, donde ya no puede universalizarse ni sexo ni género.

Hay una escena en la que Giacinto mira a través de la ventana, y lo que él observa es una mujer teniendo sexo con otra mujer, pero que no está representado como una escena de lesbianismo, ya que la práctica del sexo se concreta según las normas de lo establecido como normal entre un hombre y una mujer. En realidad, quienes cumplimentan el acto sexual es el sujeto travestido y una mujer.

En esas condiciones, a través de esa mirada, Scola representa algo que está excedido: representando una imagen de mujer, y a la vez la aparente contradicción o paradoja sobre la manera en que practican la relación sexual, de acuerdo con la imagen de un hombre que penetra a una mujer. Hay una historia de la sexualidad y de los cuerpos que se transforma, que ya no es asequible a la mirada normalizadora. Butler sostiene que

comprender el género como una categoría histórica es aceptar que el género, entendido como una forma cultural de configurar el cuerpo, está abierto a su continua reforma, y que la "anatomía" y el "sexo" no existen sin un marco cultural. (BUTLER, 2006, p. 25)

Es posible también indagar en esa lógica de multiplicidad que se desprende de la película, para pensar las prácticas de desterritorialización conjuntamente con la idea de devenir cuerpo, devenir mujer, devenir hombre, en fin, devenir un-otro, aludiendo a la significación de la imagen del veneno en el filme. En una escena de la película, el padre es invitado a un almuerzo para ser agasajado, pero en verdad se pretende envenenarlo con el objetivo de que muera y sus hijos y esposa quedarse con la casa y el dinero de una supuesta indemnización, ya sin la molesta figura de la autoridad. El objetivo no se concreta, aunque sí Giacinto come las pastas envenenadas, pero lo importante es que esa imagen del veneno funciona como ejercicio o discurso del cuerpo contaminado, lo cual se vincula con el planteamiento del exceso de lo popular en el filme. Pues, en definitiva, lo que aparece narrado entre esas imágenes es el principio escatológico del cuerpo. Este principio, esta idea del cuerpo contaminado es expresada y mostrada mediante los vómitos que sufre Giacinto después de ingerir las pastas, y la manera en que el cuerpo queda sucio y tirado sobre la orilla de un río también sucio y contaminado. Es parte del cuerpo que debe estar afuera del régimen de visualidad, el cuerpo ajeno, pero, al tiempo, al vomitar y escupir el veneno cambia su forma, retorna diferente, deviene un otro-cuerpo.

Continuando la misma línea de lo argumentado sobre el veneno, pero atendiendo a otra manera en la que Ettore Scola lo expresa y narra en la película es mediante lo que podemos llamar una cierta "lógica del basural". En varias escenas y planos de la película, los personajes trabajan con la basura, y desde ahí pueden vislumbrarse tres niveles de observación -teniendo en cuenta lo que hasta aquí se ha argumentado en el presente artículo- acerca de esos cuerpos y sus relaciones:

1 - Viven entre desperdicios

2- Trabajan con desperdicios

3- Son el desperdicio.

Esta lógica de desperdicios, habilita un pensar "fuera de la ley", es decir, la propia condición de excluidos del régimen de lo visible, la propia condición de permanecer por

${ }^{7}$ Otra manera de pensar esto en la narrativa del filme es con la escena en donde aparece el coro, la cual pareciera no tener demasiado sentido, sin embargo, el coro es narrativa y estéticamente en las tragedias griegas aquello que en su canto indica cómo va a ser la realización del destino trágico. Por su parte, en Feos, sucios y malos, y por esa propia puesta en escena de lo popular como exceso de la representación, el coro es utilizado en tanto recurso estético de la tragedia, pero puesto en el absurdo de una comedia dramática.

1468 Estudos Feministas, Florianópolis, 25(3): 1459-1471, setembro-dezembro/2017 
fuera de lo normal es lo que habilita a concebir esas prácticas que desterritorializan las imágenes normativas sobre la sexualidad y que se puedan inscribir otros discursos. La lógica de multiplicidad destituye la regulación trascendente de la ley, tal cual se observa en el envenenamiento de Giacinto, pues donde no hay padre, no hay ley. Y por eso es que mantienen relaciones sexuales entre todos, se quieren matar entre todos o se vende la casa que no tiene dueño ni título de propiedad. Retomando las nociones de Butler:

La formación, la elaboración, la orientación, la circunscripción y la significación de ese cuerpo sexuado no serán un conjunto de acciones realizadas en observancia de dicha ley [ley reguladora]; por el contrario, serán un conjunto de acciones movilizadas por la ley. (BUTLER, 2008, p. 33-34).

En síntesis, no se trata de argumentar que en la lógica de lo múltiple todo sea posible y carezca de condicionantes normativos, al contrario, lo que se habilita es una composición de la experiencia que modifica constantemente el carácter de lo normativo sin que nada permanezca fijo o establecido. Por eso, se sale de las representaciones naturaleza/cultura, sexo/género para configurar visualidades diferentes que expresan relaciones dinámicas y prácticas de desterritorialización de los cuerpos y las sexualidades.

\section{Conclusiones: sin cuerpo propio}

Desde la lógica de los muchos a la lógica de multiplicidad se postuló un recorrido analítico que propuso reflexionar sobre las modalidades de conformación y presentación de los cuerpos, atendiendo a sus líneas de desplazamiento que se sitúan entre la exclusión y su normalización mediante identificaciones de clasificación y segmentación. Es decir, ¿cómo se hace visible un cuerpo normal? En otras palabras, comprender las lógicas y condiciones de acuerdo a las cuales un cuerpo no es registro de mirada, no es presentado sobre un campo de visibilidad hasta tanto no se lo constituya como un cuerpo-que-vemos.

Por esto es necesario pensar ese cuerpo-que-vemos, en relación a la representación del cuerpo-visto. En ese punto clave se establecen las condiciones de normalización de una mirada específica sobre el cuerpo. El cuerpo popular que se integra a la regulación normativa de la sociedad burguesa es siempre según las fijaciones de un cuerpo-visto que lo resuelve apto para una mirada y, por consiguiente, para representarse en un campo de lo visible generalizado.

Remitir para este tipo de análisis a una película como Feos, sucios y malos permite desarrollar estos aspectos en relación con imágenes. La narrativa cinematográfica tiene la particularidad de impartir dos líneas de percepción: las imágenes compuestas mediantes técnicas cinematográficas que constituyen una puesta en escena, lo que es su aspecto formal, y también un ordenamiento del relato a través de situaciones específicas que se desarrollan entre escenas, lo que puede entenderse como el contenido del filme. Sobre esa relación dinámica entre forma y contenido, se generan las posibilidades de reflexión con imágenes y que ofrecen una singular manera de entender las representaciones de una mirada y de un ejercicio de lo visible.

Concretamente, en la película de Scola se expresa un trabajo sobre el orden de lo visible que promueve las estigmatizaciones sobre lo popular y los mecanismos que se generan para institucionalizar y organizar en un campo de visibilidad normalizado ese tipo de sujetos y de cuerpos. Esos cuerpos que aparecen como ajenos a las formas adecuadas de vida social, son dispuestos en otros órdenes de significación para adecuarlos a las representaciones del cuerpo-visto para formar el cuerpo-que-vemos. Eso que denominamos la lógica del menos porque segmenta y clasifica es el principio ordenador de los cuerpos 
y que en el filme se evidencia permanentemente entre las varias maneras de integración que los personajes deben considerar para alcanzar su aceptación entre los otros. Esa modalidad del dispositivo de visualidad que organiza una representación de la mirada sobre los cuerpos, sin embargo, no regula el exceso, es decir, aquello que no puede ser representado ni configurado sobre lo normal, lo que escapa al equilibrio inestable de las normas. Por ello, la lógica de multiplicidad expresa otro desplazamiento del régimen visible de los cuerpos al desterritorializarlos.

En esta línea de argumentación es posible referir al final de Feos, sucios y malos, cuando Giacinto, como venganza contra su familia que pretendió envenenarlo, vende la casa a otra familia numerosa. Esta última, en el momento que procura hacer efectiva la apropiación de su nueva propiedad, es impedida de ello por la familia de Giacinto. El desenlace es que todos terminan conviviendo en la misma pequeña casa. Pero, como se enunció antes, aquí ya no estamos en la lógica de los muchos, cuya característica era el hacinamiento, aunque siga presente la incomodidad de semejante convivencia. Los cuerpos ya se han convertidos en otros y la venta de la casa carente de título de propiedad, justamente, indica que ya no hay cuerpo propio, sino un continuo desplazamiento entre las posibilidades infinitas que esas sexualidades materializan. Es la lógica de multiplicidad y sus prácticas de desterritorialización, o como ya mostramos que teorizaba Deleuze un "cuerpo sin órganos", esto es, cuerpos que no pueden dejar de crearse porque no se pertenecen. Un cuerpo impropio que debe producir el régimen de su visualidad.

\section{Referencias}

AMADO, Ana; DOMÍNGUEZ, Nora. "Figuras y políticas de lo familiar". In: AMADO, A.; DOMÍNGUEZ, N. Lazos de familia. Herencias, cuerpos, ficciones. Buenos Aires: Paidós, 2004. p. 13-37. BATAILLE, Georges. El erotismo. Buenos Aires: Tusquets, 2006.

BAUDRILLARD, Jean. Cultura y simulacro. Barcelona: Kairós, 1987.

BREA, José Luis. Cultura_RAM. Mutaciones de la cultura en la era de su distribución electrónica. Barcelona: Gedisa, 2007.

BUTLER, Judith. Cuerpos que importan. Sobre los límites materiales y discursivos del "sexo". Buenos Aires: Paidós, 2008.

BUTLER, Judith. Deshacer el género. Barcelona: Paidós, 2006.

CITRO, Silvia. Cuerpos significantes. Travesías de una etnografía dialéctica. Buenos Aires: Biblos, 2009.

DEBORD, Guy. La sociedad del espectáculo. Valencia: Pre-textos, 1999.

DELEUZE, Gilles y GUATTARI, Félix. EI Anti Edipo. Capitalismo y esquizofrenia. Barcelona: Paidós, 1995

DIPAOLA, Esteban. "La producción imaginal de lo social: imágenes y estetización en las sociedades contemporáneas". Revista Cadernos Zygmunt Bauman, v. 1, n. 1, p. 68-84. jan. 2011 . Disponible en: http://www.periodicoseletronicos.ufma.br/index.php/bauman/ issue/view/122.

FERNÁNDEZ, Ana. Las lógicas colectivas, imaginarios, cuerpos y multiplicidades. Buenos Aires: Biblos, 2007.

HARVEY, David. La condición de la posmodernidad. Investigación sobre los orígenes del cambio cultural. Buenos Aires: Amorrortu, 2008.

NAVARRO PÉREZ, Patricia. La Despatologización de las Identidades Trans. Una Política de

Articulación Trans-Feminista. 2010. Tesis (Master en estudios de género y desarrollo profesional). Universidad de Sevilla, Sevilla. 
PEIRONE, Fernando. Mundo extenso. Ensayo sobre la mutación política global. Buenos Aires: Fondo de Cultura Económica, 2012.

SIBILIA, Paula. La intimidad como espectáculo. Buenos Aires: Fondo de Cultura Económica, 2008.

VOLÓSHINOV, Valentín. El marxismo y la filosofía del lenguaje. Buenos Aires: Ediciones Godot, 2009.

[Recebido em 08/06/2015,

reapresentado em $27 / 04 / 2016$

e aprovado em 14/05/2016]

Imaginal Narratives of Bodies and Sexualities: Gender and Corporalities in the Film Feos, sucios y malos

Abstract: Based on theoretical references about the conception of the "imaginal", that is, modes of constitution of bodies and sexualities through images, this analysis will concentrate on the film "Feos, sucios y malos" (Brutti, sporchi and cattivi) (1976) directed by Ettore Scola, aiming at observing the visualities of the body and its transformations when presented as excess of the representations. In the film, bodies, sexuality and desires mark the excesses of the representation of the popular and, therefore, a rupture of the visual normality of bodies. Thus, the representation of women and other sexual identities are woven between the axes of a normalizing gaze that the film raises to the grotesque as a means of criticism. The analysis of "Feos, sucios y malos" questions, in the criticism, the dominant and normalizing forms of inscribing the sexualities in visual devices of contemporary signification.

Key words: Bodies; Sexualities; Images; Multiplicity; Popular Classes

Esteban Dipaola (estebanmdipaola@gmail.com) es investigador en el Consejo Nacional de Investigaciones Científicas y Técnicas (CONICET) y profesor regular de la carrera de Sociología en la UBA y de posgrado en maestría y doctorado en la misma institución. También es profesor de la carrera de Filosofía en la Universidad de Ciencias Empresariales y Sociales (UCES). Es director de proyectos PICT de investigación académica en la Agencia Nacional de Promoción Científica y Tecnológica (ANPCYT). 